\title{
An Evolutionary Approach to the Theory of Entrepreneurship
}

\author{
Thomas Grebel, Andreas Pyka, Horst Hanusch* \\ June 2001
}

\begin{abstract}
The building blocks of our model are bounded-rational actors with specific sets of endowments: 'entrepreneurial spirit', human capital and venture capital. The entrepreneurial behavior to found a firm is triggered by the individuals' endowments, their social network and the evaluation of the economic situation. Bandwagon effects occur when high growth rates in emerging markets increase firm entries and firm entries in return increase growth rates until competition unfolds its selective power. The firms' survivability is determined by its founders endowments and its competitiveness. If actors are right or wrong in evaluating their economic situation and their consequent decisions is proven ex post. Thus, there will be winners and losers.
\end{abstract}

Keywords: entrepreneurship, human capital, venture capital, social networks, evolutionary economics, swarms of innovations.

JEL-Classification: O3, M13. *Department of Economics, University of Augsburg, 86135 Augsburg, Germany, e-mail:
Thomas.Grebel@wiso.uni-augsburg.de/Andreas.Pyka@wiso.uni-augsburg.de 


\section{Introduction}

Research on entrepreneurship has always been a controversial topic in economic theorizing. The significance of entrepreneurship is emphasized by almost all authors working on innovation economics, nevertheless, most of the research work comes to an end at a purely appreciative level. Still, a consistent theory of entrepreneurship is missing; a theory that is adequate to combine the various strands of literature in order to come to an empirically testable model, eventually. Besides the early theories that approach entrepreneurship from a rather intuitive perspective, to be traced back to Schumpeter (1997), Schumpeter (1939), Kirzner (1973) and Kirzner (1999), a modern evolutionary approach should also contain some specific theories such as the theory of human capital (e.g. Schlutz (1975), social networks (e.g. Granovetter (1983)) and Neo-Schumpeterian Economics (e.g. Loasby (1999)). In the following paper we develop an eclectic approach by designing an analytical model open to be applied to different industries and historical settings.

Core element of our model are the actors. Even though there are two bipolar views that either explicitly focus on actors or take a more general approach emphasizing the actors' environment only, for our purpose we draw on the actor-centered perspective. Therefore, we do not look at them from the perspective of a situative determinism and optimal behavior, but we characterize the individual actors as procedural rational, struggling in a trial-and-error process for survival and prosperity. Consequently, in their entrepreneurial decision they do not know the potential economic outcome but experimentally try different combinations. The actors in our model are heterogeneous in their individual endowment concerning their accumulated human capital, their available venture capital as well as their entrepreneurial attitude. We furthermore stress the importance of individuals' networks in the process of firm foundation as a social phenomenon. The formation of social networks is approximated by a random permutation process within our population of actors. In detail, an arbitrary number of actors, not yet involved in a firm, are randomly matched in each period. The comprehensive endowment of the group's actors constitutes their potential to found a firm. Whether a new firm is founded or not depends on their respective environment. In particular, they take into account the industry's economic development. As they obviously do not have perfect knowledge about all critical factors which drive an industry's development, they evaluate the average industry's performance by a chosen set of economic indicators. These evaluation criteria can be seen as the actors' threshold to establish a firm. Only in those cases where the actors' perceived comprehensive endowment appears to be sufficient to enter a market and the expected economic future signals promising rewards, a new firm is born. Doing this, the birth process has an influence on the industry level, which in return has a feedback effect on the micro-level which is the future decision process of others to found a firm. Thus we manage to model a micro-macro relationship which is essential for the endogenous evolution of the foundation threshold, taking place in historical time.

Whereas the act of founding a firm depends on the individuals' perceptions and on the evaluation of their current (micro- and macro-economic) situation, the firm's economic success, once founded, is determined by the individuals' resources and their specific managerial capabilities, which are embedded in the combination and complementarities of their skills. In short; their human capital. Accordingly, in the short run, the survival of the firm decisively depends on a balanced relationship be- 
tween human capital and venture capital. Missing human capital cannot be substituted by venture capital and eventually might lead to insolvency. As the firm has to invest its funds profitably within a certain period of time it faces a bottleneck in human capital in the case of a maladjusted relationship. In the long run, however, the economic success of a firm depends on its competitiveness, which in our model - for the sake of simplicity - is determined by its stock of human capital and its learning capabilities to improve on it. If the firm has to exit, again, this has a feedback effect on the foundation threshold. Due to the heterogeneous composition of actors and their experimentally organized behavior, our model is illustrated numerically for the time being. In our first simulation experiments we are able to show the emergence of new industries and their endogenous evolution from a theoretical stance. Firms do not appear continuously but in swarms showing a high degree of sensitivity to the coincidence of entrepreneurial behavior and environmental conditions. Our model is designed in a very general way and the promising results achieved so far advocates to apply this basic setting to recent empirical observations of developments of new industries. Finally, this should improve our knowledge about conditions favoring/hindering the up-coming of successful knowledge-intensive industries such as the information technology and biotechnology sector, respectively. This will be the agenda for our future research.

\section{Theoretical motivation}

\subsection{A Historical sketch and a conglomeration of entrepreneurial functions and ideas}

The importance of entrepreneurial behavior for economic development has always been stressed in economic history but the existence of entrepreneurship in orthodox economic theory has almost been undetectable. Economists wonder why the entrepreneur has almost vanished in economic theory. ${ }^{1}$ The reason apparently is that with the introduction of entrepreneurial behavior in orthodox theory a model runs the risk to lose its consistency, and therefore the entrepreneur still remained a stranger in economic theory. Classical economists touched this subject matter more than neoclassical theory, based on the equilibrium concept, might ever be able to do. Its strict, methodological apparatus appears to rule out the possibility to pick out an endogenous equilibrium-disturbing element as the center piece of economic development.

The first who took up thinking about the role of entrepreneurs in economy was Cantillon (1680's - 1734). ${ }^{2}$ He classified the economic agents into three groups: (1) landowners (2) entrepreneurs and (3) hirelings. ${ }^{3}$ Whereas the first and the third group are characterized as being rather passive, the entrepreneurs play the central part in his Essai sur la nature du commerce en général. They play the role of the coordinator connecting producers with consumers, and, additionally, the role of the decision maker engaging in markets to earn profits and struggling with uncertainty. His concept

\footnotetext{
${ }^{1}$ Barreto (1989)

${ }^{2}$ Cantillon (1931)

${ }^{3}$ see Hébert and Link (1982) for an overview.
} 
of uncertainty was constrained to the entrepreneurs, though, and it had to wait for Frank Knight $(1921)^{4}$ for a detailed distinction between risk and uncertainty as an economy-wide feature affecting all economic agents. Cantillon was also the first who emphasized the entrepreneur's economic function while distinguishing it from the agents' social status. A functional perspective was maintained by Cantillon's successors associated with the French school. Quesnay ${ }^{5}$, the precursor of 'The Physiocrats', shifted the field of concentration to the significance of capital for economic growth, thereby reducing the role of the entrepreneur - instead of an industry leader - to a pure independent owner of a business, though endowed with individual energy, and intelligence. ${ }^{6}$

Baudeau (1919) ${ }^{7}$ was the first to suggest the function of the entrepreneur as an innovator and thus brought invention and innovation into the discussion. Furthermore, he emphasized the ability to process knowledge and information, which makes the entrepreneur a lively and active economic agent. Another rather capitalistic view was set up by Jacques $\operatorname{Turgot}^{8}$ (1727-1781). According to him, the entrepreneur is the outcome of a capitalist investment decision: The owner of capital either can simply lend his money and just be a capitalist, or decide to buy land for lease and, hence, become a landowner, or he decides to buy goods to run a business and thus become an entrepreneur automatically. Jean-Baptiste Say $(1767-1832)^{9}$ continued Turgot's ideas $^{\prime}$ and elevated the entrepreneur to a key figure in economic life. In contrast to Turgot he made a sharp distinction between the entrepreneur and the capitalist. The entrepreneur might give capital to a firm but he does not have to. Consequently, this also allows for a negligence of risk and uncertainty, ${ }_{1}^{10}$ when considering the entrepreneurial element explicitly. Say suggested a twofold approach. He looked at the entrepreneur from an empiric perspective to find out the actual entrepreneurial behavior which he tried to reduce in a second step to a general entrepreneurial theory by subtracting all incidental aspects attributable to certain social and institutional circumstances. ${ }^{11}$ The function of his entrepreneur was to understand technology and to be able to transfer that knowledge into a tradable product that meets the customers' needs.

Say paved the road to Schumpeter's theory on entrepreneurship. And Schumpeter's entrepreneurial concept has to be seen as the pivotal point in this field of research. Most of the economists before Schumpeter - with some exceptions - worked within equilibrium theory and most of the theories on entrepreneurship after Schumpeter are built on his ideas. ${ }^{12}$

Before we proceed to the discussion of Schumpeter's concept, we briefly have to expose the neoclassical treatment of the entrepreneur.

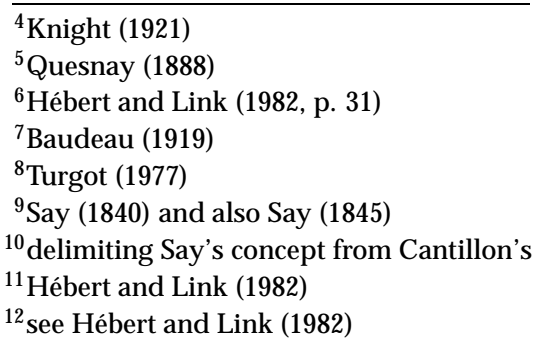




\subsection{Neoclassical Constraints}

The question "What about the entrepreneur in orthodox neoclassical theory?" is easy to answer, but it takes quite an effort to set out the argumentation. The answer is: There is no space for an entrepreneur in neoclassical theory. The according discussion can be found in Barreto (1989)'s work 'The Entrepreneur in Microeconomic Theory', where he portrays the disappearance of the entrepreneur in economic theory. ${ }^{13} \mathrm{He}$ shows that on the advent of the modern theory of the firm, economists lost track of the entrepreneur. Basically, the assumptional framework does not allow for a consistent implementation of entrepreneurial behavior. The bone of content is rooted in the perfect rationality assumption which is a necessary condition for optimal behavior. This does not allow for a 'real' choice and the treatment of true uncertainty subject to entrepreneurial behavior, which burns down the role of the entrepreneur to a static and passive and therefore redundant economic agent within a self-running firm. It is beyond the scope of this paper to recount the anamnesis of the entrepreneur in economic theory. Basically, Schumpeter's legacy can be regarded as the outcome of such kind of reflection.

\subsection{Schumpeter's entrepreneur}

To tell the story the right way, we cannot start right at Schumpeter's concept of the entrepreneur. As mentioned above, Schumpeter's work was tremendously influenced by a critical review on equilibrium theory. Though fascinated by Walras' system of equilibrium, he stated that equilibrium theory contributed as much as it can; but further insights cannot be expected. ${ }^{14}$ Schumpeter's circular flow is a less formal representation of Walras' general equilibrium theory. ${ }^{15}$ To reach equilibrium, Schumpeter suggests that economic actors' decisions and actions have to be repeated over and over again in the same way, so that eventually all actors' plans coincide to end up in equilibrium. This result Schumpeter calls a static situation that does not allow for change. ${ }^{16}$ His aim was to investigate the dynamics behind the empirically observable economic change. The explanatory element he called innovations, the economic agent to bring along innovations (i.e. "new combinations") he called the entrepreneur.

When we look back to the existing literature at that time, Schumpeter's entrepreneurial concept is a synthesis of, firstly, Say's and Badeau's work and, secondly, the critique

\footnotetext{
${ }^{13}$ Barreto (1989)

${ }^{14}$ Surely, Walras was not the only one who influenced Schumpeter's thinking. There are many others that delievered preparatory work such as Marx, Weber, Menger, Wieser, Say, Hayek, Böhm-Bawerk to name a few. But as the equilibrium concept being the bone of content we quote Warlas in this context. See Hébert and Link (1982) for a quick overview.

${ }^{15}$ Although Schumpeter was fascinated by Walras concept of equilibrium, the bifurcation point of their intellectual paths originated in the different treatment of the subject. Walras thought it to be permissible to abstrahize beyond the adjustment processes in an economic system starting right at the end, which is the equilibrium (See Walras (1995)). Schumpeter concentrated more on the process that destroys equilibrium and, if at all, might lead to equilibrium.

${ }^{16}$ Barreto (1989)
} 
associated with the Austrian school. ${ }^{17}$ Schumpeter's entrepreneur was and still is the most renowned concept. Therefore, we also take it as the intellectual foundation of our model. Another economist to be mentioned in this context is Israel Kirzner.

\subsection{Kirzner and the Austrian school}

There is a long-lasting debate, partly stirred up by Kirzner himself, about what the significant difference between Schumpeter's an Kirzner's entrepreneur is. Both Schumpeter and Kirzner took up on the Austrian critique on general equilibrium theory. Whereas Schumpeter developed a - to our minds - more general approach to entrepreneurship starting out at economic change, Kirzner focused on the market process. For the reader's convenience, the intuition of the Austrian school is to be recalled briefly: Equilibrium theory neglects market processes. If all plans of economic actors match, then, there is no need for markets. In a state of disequilibrium, however, actors' plans do not match. They have to be revised and adapted to the new market situation. ${ }^{18}$ The economic agents have to change their minds continuously and thus generate a dynamic process which Kirzner calls the market process. ${ }^{19}$ That suggests to make a Robbins-type of maximization calculation ${ }^{20}$ impossible. Mises $^{21}$ solved this task by introducing human action. ${ }^{22}$ Besides the agents' attempt to calculate economic problems, they are also alert to opportunities. Once an economic agent recognizes a market opportunity, he acts on it to improve his position. And opportunities are abundant in a situation of disequilibrium. That is where Kirzner's entrepreneur comes from. While von Mises admitted the ability of human action to every economic agent, Kirzner confined it to a certain group of agents which he labeled entrepreneurs. Hence, the entrepreneur, as an arbitrageur that equilibrates markets, was born. ${ }^{23}$

\subsection{A word on the Schumpeter-Kirzner-entrepreneur discussion}

Kirzner himself ${ }^{24}$ distinguished the Schumpeterian entrepreneur, as the innovator and the creative destructor of equilibrium, from his own, the equilibrating entrepreneur alert to market opportunitites. We leave it two the reader's taste to make this distinction between an equilibrium-disturbing and an equilibrium-creating entrepreneur.

\footnotetext{
${ }^{17}$ Ludiwg von Mises and Friedrich von Hayek as the alleged leaders of the Austrian school engaged in the analysis of disequilibrium conditions focusing on market processes. To get a good intuition of Hayek's attitude towards mainstream economics, see Hayek (1990). Concerning Ludwig von Mises, some necessary amendments will be given when introducing Kirnzer's entrepreneur later on in this paper.

${ }^{18}$ This is the point to stress the role of information and knowledge as Hayek, Mises and Kirzner do.

${ }^{19}$ Kirzner (1973, p.10)

${ }^{20}$ Robbins puts forward the economic agents task to economize on scarce resources efficiently. But Efficiency is no more possible in an Austrian-school-like market-process (Robbins (1962)).

${ }^{21}$ von Mises (1959)

${ }^{22}$ Barreto (1989, p.17)

${ }^{23}$ Barreto (1989, p.21)

${ }^{24}$ Kirzner (1999)
} 
As a matter of perspective, if we allow to think of the alertness to market opportunities and the agent's implied human action as being a part of innovativeness neglecting the question whether a state of equilibrium in a dynamic economic world will ever be reached before another dynamic entrepreneur comes to prevent economy from equilibrium, it would leave us with the center-piece of the Schumpeterian dynamics of economic change, i.e. the entrepreneur. In short, Schumpeter's stream of consciousness looks as follows: No entrepreneur - no innovation - no dynamics - no evolution.

\section{6 "Giving up the Grail"}

Ever since economists started to theorize on human behavior, they have been looking for consistency in theory. What classical theorists could not achieve, neoclassical economists succeeded in. The marginal school and in particular the Walrasian general equilibrium theory eliminated the shortcomings in terms of inconsistency within economic theory. They managed to refine the patchwork of classical thoughts to a consistent unity, but - as we see from the discussion above - at the cost of the entrepreneur. On the contrary, if we give up on the equilibrium concept, for the sake of the entrepreneur, we might run the risk of losing consistency in return. Then, we have to do disequilibrium economics without such a powerful mathematical apparatus of the neoclassical school. Equilibirium needs optimal behavior. Optimal behavior needs perfect rationality. Perfect rationality requires perfect foresight and information. Regardless which of these assumptions we relax, at the same time we question the validity of the remaining ones, and, even worse, we question the methodological approach. This all foreshadows another era of patchwork in economic theory, concerning the investigation of entrepreneurship, until an appropriate methodology will be found. These misgivings can be confirmed, when we look at the existing literature which refers to entrepreneurship and at the same time abandons the equilibrium concept.

\section{An evolutionary approach to an evolutionary concept of the entrepreneur}

"...the word 'evolutionary' is extremely vague. It is now widely used, even by economists using neoclassical techniques. "Evolutionary game theory" is highly fashionable. Even Walras is described as an evolutionary economist Jolink (1996). ... In precise terms it signifies little or nothing."25

For this reason, we decided to discuss briefly what evolutionary means to our minds. The model presented in this paper is meant to be a general approach to entrepreneurship delivering constructive propositions for a basic evolutionary setting.

Consolidating the critique of Schumpeter, the body of thought from the Austrian School and, accordingly, Kirzners adaptations to the entrepreneurial case, research on entrepreneurship becomes the pivotal point of a micro-based evolutionary theory.

${ }^{25}$ Hodgson (2000) 
A lot of issues are addressed that burn down to questioning the phenomenon of innovation in an economic system. Innovation means novelty and in accordance with Arrow's epistemological reservation, an assumptional chart house built on perfect foresight (complete information), which means perfect rationality, is a contradiction in itself. It ignores economic change spurred by the dynamic entrepreneur. Each of the assumptions mentioned above entails a huge discussion leading to various strands of literature. Of course, it is not the aim of this paper to cover all of it, but they have to be taken into account, implicitly. ${ }^{26}$

Along these lines, in our model we begin at the micro-level. The agents are heterogeneous and differ in their individual endowment. Information is incomplete, in particular with respect to the future economic development. Because of imperfect foresight, agents have to deal with true uncertainty. ${ }^{27}$ Furthermore, the bounded rational ${ }^{28}$ agents are limited in their cognitive capabilities to perceive and process the accumulated information. Owing to the high degree of novelty attached to entrepreneurial behavior, true uncertainty does not allow for a calculation of expected values. The agent neither knows the set of possible outcomes nor the corresponding probabilities. As we thus deprive the agents from optimizing capabilities, they have to make decisions best to their knowledge. They have to perform, in the words of Mises, human action. Thereto, the agents have to form expectations on various respects: at first they have to evaluate their individual endowment of resources, capabilities and competencies, second, the possibilities to acquire missing complementarities (to be specified later on) and third, the "economic situation".

The light of perfect rationality missing, agents consequently make individual forecasts motivated by their personality ${ }^{29}$ and current (economic) environmental factors. To put it in other words: decisions are the outcome of a path-dependent process: the evolution of the agent's individual (accumulated) endowment (resources, capabilities, competencies (including experience)) and non-individual, environmental factors subsuming the economic situation. The latter gives us the notion of feedback effects. The economic agents' decisions are influenced by economic factors (economic situation) and in return influence economic factors by their actions, e.g. by the decision to establish a firm. It goes without saying that we implicitly consider irreversibility to round off the assumptional frame of our evolutionary perspective.

In the following, we flesh it out with some less abstract ideas of entrepreneurial behavior. Since our main intention is to show the basic structure of an evolutionary model of entrepreneurship, we decided to tolerate some simplifications.

\subsection{Actors}

We divide an agent's individual endowment into three components which we call entrepreneurial spirit, human capital and venture capital. These three factors form

\footnotetext{
${ }^{26}$ For a succinct setting of an evolutionary theory see for example Nelson (1995)

${ }^{27}$ As the reference work on uncertainty see Knight (1921) and his distinction between risk and uncertainty. In the entrepreneurial context we have to deal with 'true' uncertainty. The agent does neither know the outcome nor is he able to calculate corresponding probabilities.

${ }^{28}$ To this discussion see e.g. Simon and Egidi (1992).

${ }^{29}$ By personality we mean the conglomerate of accumulated knowledge, information and experience
} 
the individual agent. ${ }^{30}$

\subsubsection{Entrepreneurial component}

The entrepreneurial component can be thought of as the residual of the agent's individual endowment which withdraws itself from empirical measurability. It comprises the intangible characteristics of the heroic Schumpeter entrepreneur. Doing this, we follow empirical evidence that does not allow to detect a stereotypic entrepreneur and furthermore, we take up on Mises saying that every human being has the potential of human action.

\subsubsection{Human capital}

With the second component we refer to one of the more successful strands of research. The human capital approach, constituted by Theodor W. Schultz ${ }^{31}$ and elaborated by Gary S. Becker among others, ${ }^{32}$ allows for an empirical application. It tries to explain optimal investment in human capital and delivers insights on income distribution. The theoretical concept is basically derived from investment theory in physical capital using marginal analysis. We do not use the human capital concept this way, ${ }^{33}$ but we emphasize the importance of human capital for establishing a firm. Agents do not know the actual return when they decide in favor of founding a firm, they might do so when offering their human capital to the labor market. Therefore, agents decide in a dichotomous way; if they expect the returns of going entrepreneurial will be higher than being an employee, they will decide to become an entrepreneur.

Moreover, we refer to the literature on knowledge originating from the Austrian School, ${ }^{34}$ which discusses the importance of knowledge in a disequilibrium situation - that is - a situation of uncertainty. Loasby (1999) gives a good intuition on "Knowledge, Institutions and Evolution in Economics". 35 For our purpose, we interpret the agents' role of human capital as the crucial productive element for the long-run survival of the firm, once it is founded by the agents.

\subsubsection{Venture capital}

The third element we include into the agents' endowment vector is the component of venture capital. Herewith, we pay tribute to the discussion whether "the roles of

\footnotetext{
${ }^{30}$ Each component is the result of a cumulative evolutionary process which will not be discussed in this paper. With respect to an empirical application, each component requires sector-specific observations. ${ }^{31}$ Schlutz (1971)

${ }^{32}$ Becker (1993)

${ }^{33} \mathrm{We}$ are conscious of our tightrope walk to use a strictly neoclassical concept within our model that we explicitly claim to be evolutionary. We assume a link between the agents' set of capabilities and their economic performance. For the time being, we rather use it as a metaphor to stress the importance of knowledge in our model leaving the necessary "evolutionary" clarification of this concept for further research.

${ }^{34}$ Hayek (1990)

${ }^{35}$ Loasby (1999)
} 
capitalist and entrepreneur" can be separated. The "early French view" rather saw the entrepreneur as a risk bearer; the "English view" identified the entrepreneur as the capitalist. Schumpeter (1939) discusses the role of money, too. ${ }^{36}$ The bottom line is that potential entrepreneurs need to have capital to start their business, no matter if they own it themselves or borrow it from others. Empirical evidence supports the hypothesis that entrepreneurs in general face financial and liquidity constraints. ${ }^{37}$

The intuition we draw out of this discussion is that we assume each agent to be endowed with a certain amount of capital he can spend on a business venture. Again, we do not bother about the details, whether he inherited or accumulated a certain amount of money by saving.

So far, we have characterized the individual agents by their endowment factors. ${ }^{38}$ Each actor possesses the potential to be an entrepreneur as von Mises suggests from a theoretic perspective and - as empirical data shows - most agents express to have. ${ }^{39}$ Thereby, the decision (human action) is no behavior of optimality, calculating what the maximal return to total - human and (free disposable) venture - capital is. Although, the long-run survival of a firm once founded is highly dependent on the agent's human capital. As we vested all agents with the option to own venture capital, we can incorporate the notion of risk bearing and uncertainty. But as we will see later on, the "mainly" ${ }^{40}$ entrepreneurial agent need not be the risk bearer. ${ }^{41}$

Even though an agent might have a certain amount of every component, necessary to establish a firm, he might not have enough of it. In that case, the agent needs to complete the minimum endowment necessary to his mind. Consequently, we introduce a network approach to entrepreneurship.

\subsection{Social Networks}

To complete the minimal endowment - whereby it still has to be defined what minimal means - actors can choose several ways to acquire these endowment factors. They have to figure out how to get access to required resources (Penrose (1959)) and whether the necessary competence to combine these resources (Foss (1993)) is available. To insinuate on Coase (1988), some of the resources and competencies can be inherent to the agent, others have to be acquired on the market or otherwise. We will not go further down this road and leave that task to a modern evolutionary theory of the firm still to be developed, ${ }^{42}$ since we do not argue on the firm level but, following Birley (1985), investigate the "pre-organization" phase in order to stress the impor-

\footnotetext{
${ }^{36}$ Schumpeter (1939)

${ }^{37}$ Blanchflower and Oswald (1995)

${ }^{38}$ Besides the suggested endowment factors any other desired factor can be included into the endowment set.

${ }^{39}$ see Blanchflower and Oswald (1995)

${ }^{40}$ As we proceed we will not confine the entrepreneurial behavior to a single agent but to a number of agents

${ }^{41}$ This goes along the lines of Schumpeter (1939, chapter: Entrepreneur)

${ }^{42}$ We could include learning into the model and thus reflect on the human capital component. Coase (1937),Penrose (1959), Demsetz (1973),Wernerfelt (1984) will definitely give enough inspiration to extent our model.
} 
tance of an agent's social network as a main source of help to obtain resources and competencies to start a business.

Furthermore, we discuss the role of social networks ${ }^{43}$ for two reasons. First, for methodological reasons: By implementing social networks into the model, we "climb up the aggregation ladder" one step further and, thus, leave the micro-level (individual's level) to bring the agent's social context into discussion. Second, for empirical reasons: personality-based theories - that is, purely micro-based theories - try to find personal traits unique to entrepreneurs. ${ }^{44}$ Nevertheless, these attempts have not yet been successful to identify the entrepreneur when not considering the social group context. ${ }^{45}$

It is beyond the scope of this paper and not our intention to discuss social network theory comprehensively. As we put together existing fragmental theories on entrepreneurship in an evolutionary model setting, with social networks we incorporate another critical element to entrepreneurial behavior. ${ }^{46}$

\section{The Model}

In the following section we introduce the basic structure of our model of entrepreneurship evolution. The model is designed in a very general form so that it will eventually allow us to investigate different scenarios and furthermore to implement relationships and specificities of certain sectors. In a way the basic design has to be seen as a platform approach allowing several extensions with regard to the theoretic perspective as well as with regard to a close look at the empirical sphere.

\subsection{The Actors}

To model the evolution of entrepreneurship and the founding of new firms, we obviously have to go one step further down the micro-level, i.e. not only down to the firm-level but to the individual actors' level and in particular to the individuals' specific endowment. The individuals are characterized by the crucial features identified in the previous section: i) entrepreneurial spirit $e s_{i}^{t}$, which describes an actor's tendency not to become an employee but an independent firm leader; ii) human capital

\footnotetext{
${ }^{43}$ Granovetter (1983)

${ }^{44}$ see Aldrich and Wiedenmayer (1993) as an example.

${ }^{45}$ Hall (1982)

${ }^{46}$ In case agents do not have a sufficient set of endowments and, hence, need additional resources, complementary assets and competencies, networking plays an important and a manifold role. Not only provides the social network the opportunity to have access to additional and complementary endowment factors, networks have a crucial influence on the actual entrepreneurial decision to start a venture itself. Suppose a single agent thinks himself not to be able to start a business all by himself, he has to convince others in order to be supported. Otherwise, the lack of legitimacy may prevent entrepreneurial actions. Whereas a high degree of innovativeness, the so-called liability of newness, might be ended by an agent's objecting social network, a synergetic outcome of either strong or weak ties within a network can be an enhanced and by the group subjectively high-valued business idea. In other words: a social network functions as a catalyst to spark a venture. See Efring and Baden-Fuller (2000).
} 
$h c_{i}^{t}$, representing an actor's specific level of technological as well as economic knowledge and skills and finally the actor's endowment and/or access to venture capital $v c_{i}^{t}$. These different features are all represented as real numbers on a cardinal scale in the interval [0,1], higher values indicating higher levels of the specific characteristics. Accordingly, the $n$ different actors in our model are described by the following triple:

$$
a_{i}^{t}=\left(\begin{array}{c}
e s_{i}^{t} \\
h c_{i}^{t} \\
v c_{i}^{t}
\end{array}\right)
$$

where $a_{i}^{t}:=$ actor $i$ at time $t, i \in\{1, \ldots, n\}$. To build a starting distribution of the population of actors (2) we create randomly $n$ of these triples where the features $e s_{i}^{t}$, $h c_{i}^{t}$ and $v c_{i}^{t}$ are uniformly distributed within the relevant interval.

$$
A^{t}=\left\{a_{i}^{t}\right\}_{i \in\{1, \ldots, n\}}
$$

\subsection{Matching Process and Founding Threshold}

For each iteration the population of actors not yet involved in a firm is permuted and $k$ different actors are randomly brought together in order to evaluate their chances to found a possibly successful firm. For this purpose, we consider the specific attributes of the actors to be additive so that also a potential firm $p f_{q}^{t}$ can be characterized by the triple of attributes of its $k$ members:

$$
p f_{q}^{t}=\left(\begin{array}{c}
\sum_{i=1}^{k} e s_{i \in k_{q}^{t}}^{t} \\
\sum_{i=1}^{k} h c_{i \in k_{q}^{t}}^{t} \\
\sum_{i=1}^{k} v c_{i \in k_{q}^{t}}^{t}
\end{array}\right)
$$

so that the set of potential firms at time $t$ is

$$
P F^{t}=\left\{p f_{q}^{t}\left(=c e_{q}^{t}\right)\right\}_{q \in\{1, \ldots, m\}}
$$

where $q \in\{1, \ldots, m\}$ denotes the specific potential firm and $m$ the number of potential firms, i.e. the number of temporarily formed $k$-groups $q$ in period $t$. Each group of actors has to evaluate if their comprehensive endowment $c e_{q}^{t}$, which for simplicity is equal to $p f_{q}^{t}$, is adequate. Yet, the actors' mere perception of their common resources, attitudes and motivation is not the only determinant for founding a firm. The actors involved are also influenced by their environment and the respective mood within the population. For modelling reasons, we introduce the so-called founding or entry threshold $\Psi^{t}$, a "meso-macroeconomic signal" which endogenously depends negatively on the growth rate of the sector's turnover $w^{t}$ which in return decreases the threshold. Furthermore it depends positively on the rate of exits $d^{t}$ of firms in the respective industry which increases the threshold:

$$
\Psi^{t}=\Psi\left(\frac{d w^{t}}{d t}, d^{t}\right)
$$

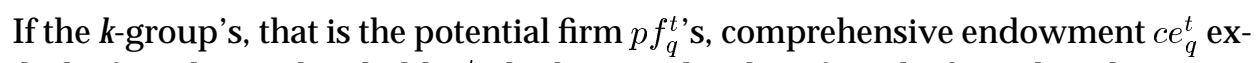
ceeds the foundation threshold $\Psi^{t}$, the $k$ actors decide to found a firm, thus the potential firm $p f_{q}^{t}$ turns into an actual firm $f_{j}^{t}$, and the formerly potential firm's comprehen- 
sive endowment $c e_{q}^{t}$ becomes the actual founded firm's comprehensive endowment $c e_{j}^{t}$. (6) gives the set of newly founded firms $F_{\text {new }}^{t}$ in period t:

$$
F_{\text {new }}^{t}=\left\{p f_{q}^{t}: p f_{q}^{t}>\Psi^{t}\right\}_{p f_{q}^{t} \in P F^{t}}
$$

Hence, the set of all firms that have been founded up to time $t$ is given in (7), whereby (8) gives the firm j's comprehensive endowment.

$$
\begin{gathered}
F^{t}=\left\{f_{j}^{t}\right\}_{j \in\left\{1, \ldots, x^{t}\right\}} \Leftrightarrow \bigcup_{0}^{T} F_{\text {new }}^{t} \\
f_{j}^{t}=c e_{j}^{t}=c e\left(\sum_{i=1}^{k} e s_{i}^{t}, \sum_{i=1}^{k} h c_{i}^{t}, \sum_{i=1}^{k} v c_{i}^{t}\right)_{j \in\left\{1, \ldots, x^{t}\right\}, i \in a}
\end{gathered}
$$

If the threshold is not exceeded, the option to found a firm, for the time given, is rejected by the actors. Consequently, the actors that do not get engaged in a firm are free to go for further trials in the following period. In the case of a successful foundation of a firm $f_{j}^{t}$ with $j \in\left\{1, \ldots, x^{t}\right\}$ the $k$ actors involved are no longer available to found another firm. At the same time, this reduces the probability for other actors to find adequate partners. On the other hand, according to equation (9) the number of existing firms $x^{t}$ is increased by the number of firms $F_{\text {new }}^{t}$ founded within a period, thereby also exerting a positive influence on the sector's aggregate turnover which positively feeds back on the founding threshold in the next period.

$$
x^{t}=x^{t-1}+\left|F_{\text {new }}^{t}\right|
$$

$x^{t}:=$ number of firms in the industry at time $t$.

\subsection{Survival and Exit}

Whether a firm $f_{j}^{t}$ survives in the market or is threatened by exit critically depends on its set and composition of aggregated capabilities as well as on the turnover that firm is able to acquire. Most simply, we assume for a firm's turnover that it is positively influenced by its aggregated human capital $h c_{j}^{t}=\sum_{i=1}^{\infty} h c_{i}^{t}$ and its aggregated venture capital $v c_{j}^{t}=\sum_{i=1}^{\infty} v c_{i}^{t}$. In order to approximate a positive influence of experience also the accumulated turnovers $\sum_{t} w_{j}^{t-1}$ exert a positive influence:

$$
w_{j}^{t}=w\left(\alpha \cdot h c_{j}^{t}, \beta \cdot v c_{j}^{t}, \gamma \cdot \sum_{t} w_{j}^{t-1}\right)
$$

$\alpha, \beta, \gamma:=$ weighting parameters.

Finally, in cases where the composition of a firm's $f_{j}^{t}$ specific characteristics shows an unfavorable relation with respect to a relatively low amount of human capital $h c_{j}^{t}$ compared to its venture capital $v c_{j}^{t}$, we introduce a so-called burning rate $w_{j}^{t}$ (equation (11)) which depreciates the available capital in the course of time according to equation (12): 


$$
\begin{gathered}
\omega_{j}^{t}=\left\{\begin{array}{cc}
0 & \text { if } \frac{h c_{j}^{t}}{v c_{j}^{t}} \geq 1 \\
\frac{h c_{j}^{t}}{v c_{j}^{t}} & \text { if } \frac{h c_{j}^{t}}{v c_{j}^{t}}<1
\end{array}\right. \\
v c_{j}^{t}=v c_{j}^{t}-\sigma \cdot \omega_{j}^{t}
\end{gathered}
$$

$\sigma:=$ weighting parameter. A firm has to exit the market in the cases its venture capital $v c_{j}^{t}$ is reduced to zero.

\subsection{Basic Structure of the Model}

Figure 1 summarizes the basic structure of the model.

To start with, we distinguish several levels of analysis: the actors level, the firm level and the sector level. The entrepreneurial process primarily takes place on the actors level. A set of actors with heterogeneous endowments is given. Actors form social networks that change over time, expressed by a random matching process. The actors, grouped together, constitute a potential firm. Since they neither have per-

Figure 1: Basic structure of the model

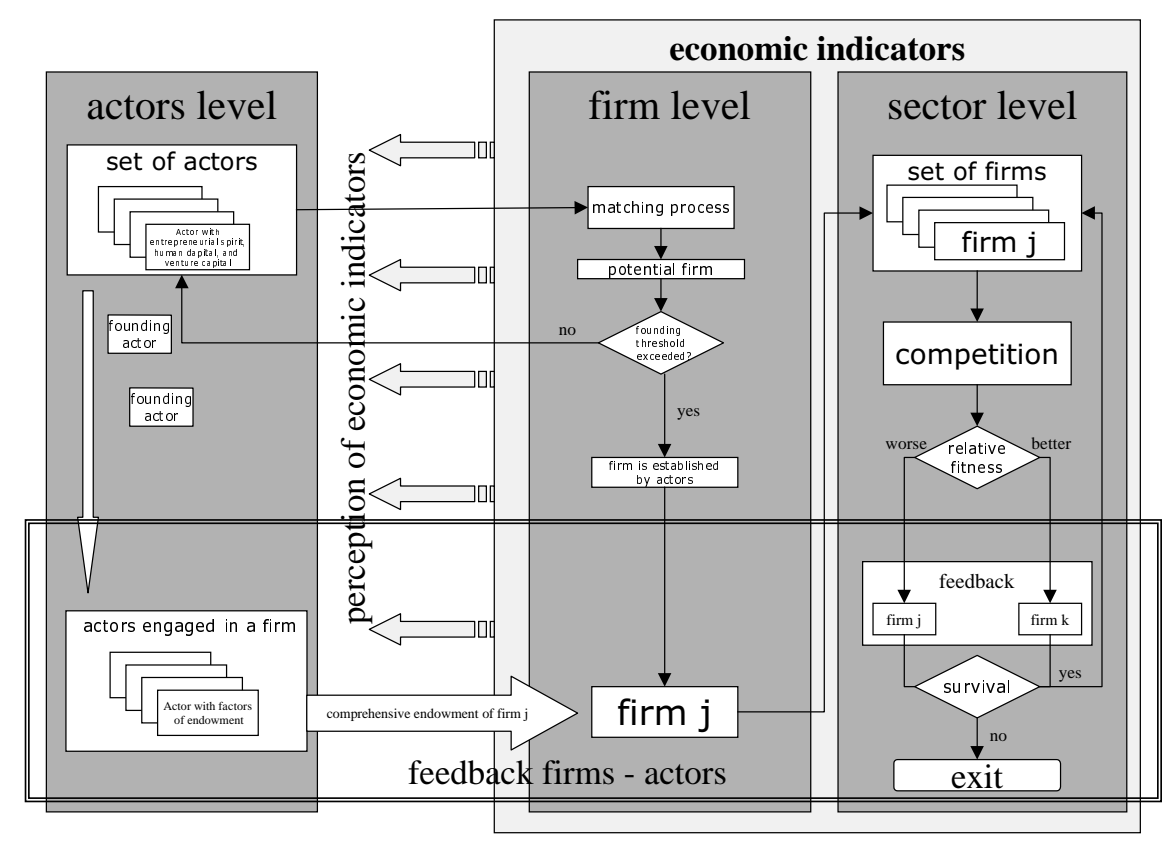

fect foresight nor complete information about future prospects, their decision will be 
myopic, based on their common evaluation of the economic situation which is influenced by their subjective perception of measurable economic indicators. The more economic indicators paint a promising picture of a possibly prosperous outcome of entrepreneurial actions, the lower the threshold for actors to decide in favor of such action. The same holds vice versa. If actors decide against founding a firm, they return to the set of actors available for another trial to evaluate entrepreneurial actions within a changed social environment. If they decide to found a firm, the firm is established and actors' resources are bounded within the firm so that they are excluded from a further firm founding process. On the sector level, the firm is forced to compete with incumbent firms. Their competitiveness is determined by their comprehensive set of endowments constituted by the founding actors individual endowments. The selection process, which is competition, has an effect on each firm either worsening or improving its fitness to stand future competition. The short-run exit criterion, competing "for the market", is insolvency. Firms with an unbalanced set of endowments run out of money and finally have to exit the market. The long-run selection process via market competition, or to put it in other words "competition in the market", decides over the competitiveness of the actual business idea.

\section{Results}

In this section we present some of the first simulation results of the model. Though our focus is put on entrepreneurial behavior, we have to take a rather holistic view. Combining the manifold theoretical contributions in the realm of the analysis of entrepreneurial behavior, we also have to touch some peripherals of the subject investigated in order to show the endogenous dynamics of entrepreneurship. Otherwise, it would not be possible to include the feedback effects suggested in the model. Nevertheless, we neglect a further specification of those peripheral, economic phenomena and leave it with a purely theoretical case. The simulations, we ran, all show the same qualitative features. A Monte-Carlo simulation to support our findings still has to be done. To start with a stereotypical development of the emerging sectors' total

Figure 2: Overall turnover of the emerging sector

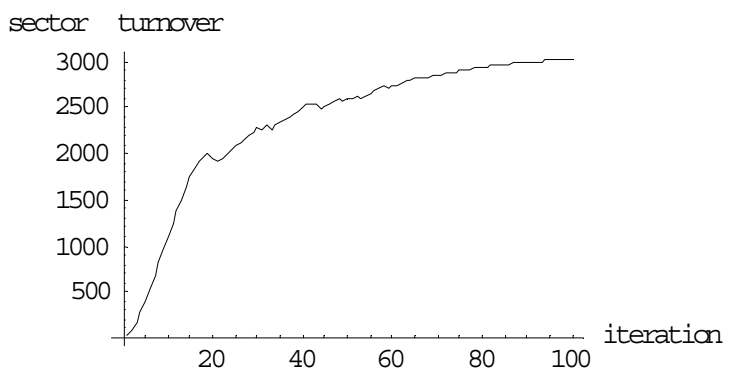


turnover, see figure 2. Once firms are founded, the industry's total turnover increases sharply. The high growth rates at the beginning function as a signal for other economic actors to enter the market (to innovate), too. From a certain point in time on, as competitive pressure increases, with more and more firms entering the market and as market diffusion proceeds, growth rates decline though remaining positive. Thus, the total turnover curve takes a stylized sigmoid shape. Firms do not enter all at once. Some enter early whereas others enter at a later point in time. Early entrants might have a first-mover advantage whereas late entrants might have to struggle for survival competing with larger firms. It is not just the time of entry that makes firms different but also their set of endowments that is crucial for their economic development. Figure 3 shows the heterogeneity of firms by indicating the emerging sectors' variance in turnover.

Figure 3: Variance of turnovers

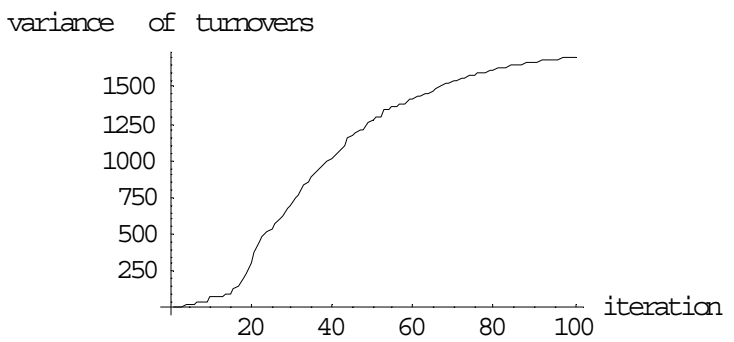

Taking a closer look at the firms' heterogeneity we selected some firms with a stereotypical development. In figure 4 we see what intuitively seems to be obvious, the earlier a firm enters the better it is able to increase its market share. All the same, there is no guarantee for first-movers to survive. The first-mover in the diagram dominates the market until it is outperformed by the two successive firms and eventually has to exit the market because of insolvency caused by an imbalanced set of endowments within the firm. Best practice is shown by firm 5 which is a relatively late entrant but dominates the market until the end of the simulation run. The performance, which is the growth rate, the

size and the time span of survival, is dependent on the firm's set of endowments. This should suffice for a rough description of the endogenous development of the sector as we do not discuss market structure and firm size.

With figure 5 we put forward a rather cognitive argument which we consider the guiding element of entrepreneurial behavior. Actors have to evaluate their chances to found a potentially successful firm. Due to their bounded rationality, they have to decide on grounds of their accumulated knowledge and experiences whether to found a firm or not. They make a subjective decision which is influenced by their perception of market opportunities, represented by the individuals interpretation of the economic indicators. The higher a sector's growth rates are, the better market 
Figure 4: Turnover of firms within the sector

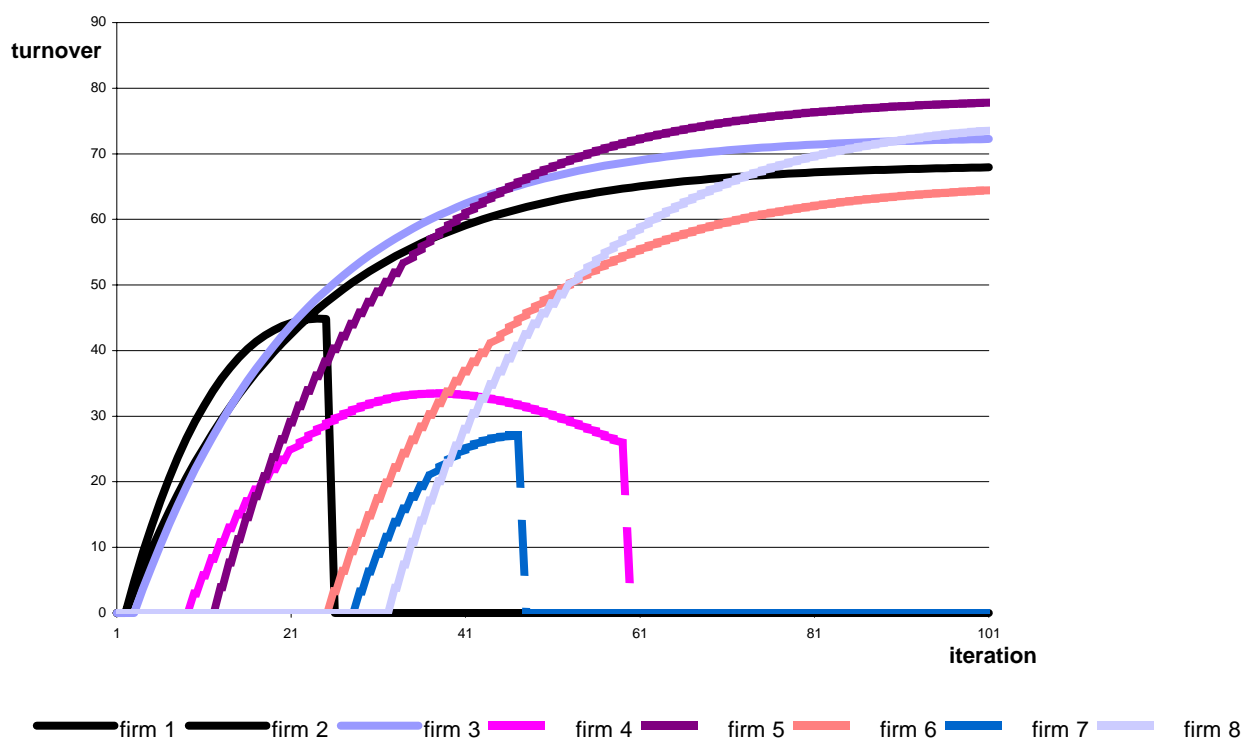

Figure 5: Founding threshold

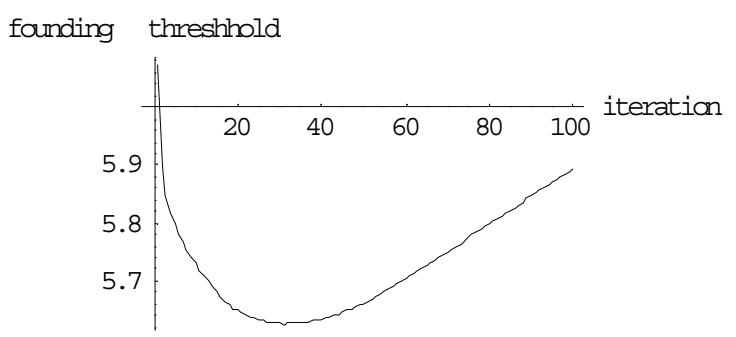


opportunities are evaluated, hence, the actors' inhibitedness for entrepreneurial behavior decreases and more and more firms are founded. Thus the foundation threshold decreases until compensating effects set in: With an increasing number of firms in the market, the competitive thread is increased. Furthermore, growth rates shrink and some firms already have to exit the market. As economic indicators get worse the foundation threshold starts rising. Correspondingly, we observe a swarm of entrepreneurs (figure 6) along the plummeting foundation threshold and a decreasing number of firm entries when exits occur first. The foundation threshold starts rising again. Fewer actors evaluate market opportunities positive and found a firm. Exits exceed entries (figure 7).

Figure 6: Number of new firms per period

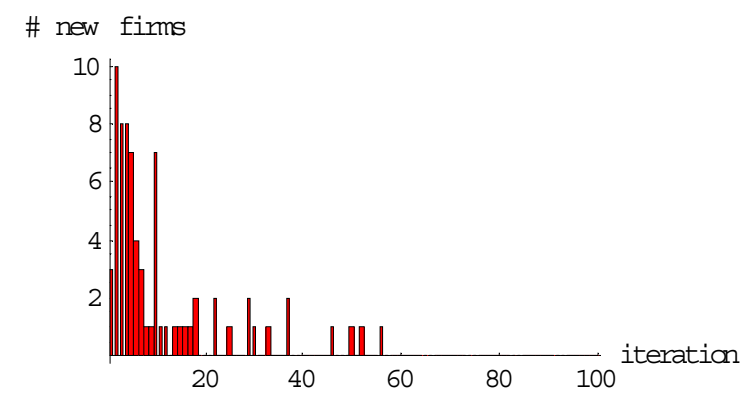

Figure 7: Net entries per period

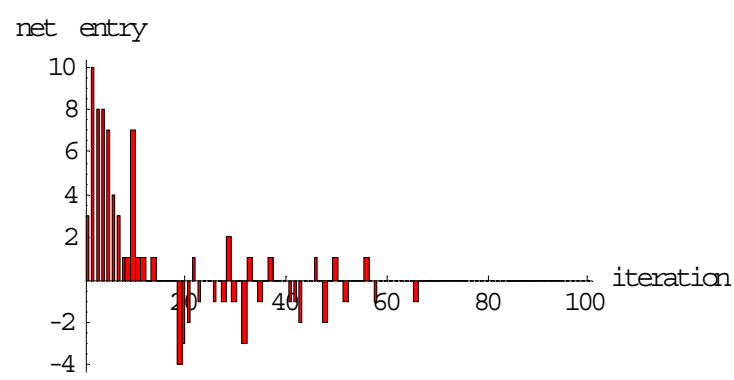

Since we have only introduced the sector's growth rate in turnover and the number of exits as two of many other measurable economic indicators influencing the actors perception of the real economic situation, the founding threshold keeps on rising 
after plummeting once. Therefore, the formation of new firms fades out gradually. So do exits, as we have not yet implemented the long-run selection process, "competition in the market". This shows that there are still some chores to be done in our future research work.

\section{Concluding Remarks and further Research}

We developed a model of entrepreneurial behavior which we claim to be an evolutionary one. Once again, we emphasize that we explicitly consider the entrepreneurial behavior, the birth process of firms and industries; a further discussion of the industry life cycle is not intended. The core elements of the model are the heterogeneity of actors, their bounded rational behavior to make myopic decisions in favor of founding a firm (which might eventually lead to sub-optimal outcomes), the feedback effects from the micro- to the macro- level and vice versa, the (irreversible) historicity of events and the variation and selection mechanisms that put the economic process into a dynamic context.

Not using an equilibrium concept and nor assuming optimal behavior, we manage to avoid a "survivor bias" at least from a theoretical point of view: some actors decide to run a firm even though they have to exit in the short run because of a lack in the necessary and adequate comprehensive endowment.

Economic change is brought along, firstly, by the actual economic development driven by the market process and, secondly, by the changing attitude of actors driven by their perception of the economic situation.

At the beginning of the up-coming new sector, actors have to deal with true uncertainty prevailing the decision-making process; the more actors have to rely on their subjective and possibly "false" intuition concerning their entrepreneurial actions, which leads to market turbulence in the early phase of the sectors life cycle. As time goes by, actors are more and more able to understand new technologies, to assess market opportunities and their chances for a successful innovative, entrepreneurial behavior; consequently, uncertainty decreases, more precise predictions and more careful decisions will be made so that stabilizing forces set in.

Our future research work is motivated by empirical applications. Therefore, some specifications will be necessary. Starting at the actors level, we have to investigate the actors individual set of endowments in order to identify the actual essential components that spur entrepreneurial behavior, including the creative process of generating a business idea. Besides, a possible classification of actors and the formation process of their social networks that have an impact on entrepreneurial behavior have to be considered. In this context, we will have to introduce an interaction-based component into our model to illustrate the qualities of the actors' search process.

The most challenging part of our future research work will be to analyze the cognitive part of the story, which is the role of the founding threshold. It is to investigate the way economic actors perceive the economic situation and a universal metal construct comes into existence leading to a bandwagon effect in entrepreneurial actions showing swarms of innovations. 


\section{References}

Aldrich, H. E. and Wiedenmayer, G.: 1993, From traits to rates: and ecological perspective on organizational foundings, in R. H. Brockhaus and J. Katz (eds), Advances in Entrepreneurship, Frim Emergence, and Growth, JAI Press, Greenwich, pp. 145-195.

Barreto, H.: 1989, The Entrepreneur in Microeconomic Theory, Routledge, London and New York.

Baudeau, N.: 1919, Première introduction à la philosophie économique, Geuthner, P.

Becker, G. S.: 1993, Human Capital, A Theoretical and Empirical Analysis with Special Reference to Education, The University of Chicago Press, Chicago.

Birley, S.: 1985, The role of networks in the entreprneurial process, Journal of Business Venturing (1), 107-117.

Blanchflower, D. G. and Oswald, A.: 1995, What makes and entrepreneur?, unpublished.

Cantillon, R.: 1931, Essai sur la nature du commerce en général, H. Higgs.

Coase, R.: 1937, The theory of the firm, Economica .

Coase, R. H.: 1988, The Firm, the Market, and the Law, University of Chicago Press, Chicago.

Demsetz, H.: 1973, The theory of the firm revisited, Journal of Law and Economic Organization (4), 151-162.

Efring, T. and Baden-Fuller, C.: 2000, The locus of entrepreneurship: firms, networks and markets, unpublished.

Foss, N. J.: 1993, Theories of the firm: contractual and competence perspectives, Journal of Evolutionary Economics (3), 127-144.

Granovetter, M. S.: 1983, The stength of weak ties. A network theory revisited, in R. Collins (ed.), Sociological Theory, Jossey-Bass, San Francisco, pp. 201-233.

Hall, R.: 1982, Organizations: Strucutre and Process, 3 edn, Prentice-Hall, Englewood Cliffs, New-Jersey.

Hayek, F. A.: 1990, Economics and knowledge, in M. Casson (ed.), Entrepreneurship, Edward Elgar, England.

Hébert, R. F. and Link, A. N.: 1982, The Entrepreneur: Mainstream Views and Radical Critiques, 2 edn, Praeger, New York.

Hodgson, G. M.: 2000, What is the essence of institutional economics?, Journal of Economic Issues 34(2), 317-330.

Jolink, A.: 1996, The Evolutionist Economics of Léon Walras, Routledge, London and New York. 
Kirzner, I. M.: 1973, Competition and Entrepreneurship, University of Chicago Press, Chicago.

Kirzner, I. M.: 1999, Creativity and/or alertness: A reconsideration of the schumpeterian entrepreneur, Review of Austrian Economics, Vol. 11, Kluwer Academic Publishers, pp. $5-17$.

Knight, F. H.: 1921, Risk, Uncertainty and Profit, Houghton Mifflin, New York.

Loasby, B. J.: 1999, Knowledge, Institutions and Evolution in Economics, Routledge, New York.

Nelson, R. R.: 1995, Recent evolutionary theorizing about economic change, Journal of Economic Literature XXXIII, 48-90.

Penrose, E. T.: 1959, The Theory of the Growth of the Firm, Oxford University Press, Oxford.

Quesnay, F.: 1888, Oeuvres économicques et philosophiques, M. J. Baer, Frankfurt.

Robbins, L.: 1962, An Essay on the Nature and Significance of Economic Science, Macmillan, London.

Say, J. B.: 1840, Cours complet d'économie politique pratique, Buillamin, Paris.

Say, J. B.: 1845, A treatise on political economy, 4 edn, Grigg \& Elliot, Philadelphia.

Schlutz, T. W.: 1971, Investment in Human Capital, Free Press, New York.

Schlutz, T. W.: 1975, The value of the ability to deal with disequilibria, Journal of Economic Literature 13, 827-846.

Schumpeter, J. A.: 1939, Business Cycles I, McGraw-Hill, New York.

Schumpeter, J. A.: 1997, Theorie der wirtschaftlichen Entwicklung, 9 edn, Duncker \& Humblot, Berlin.

Simon, H. A. and Egidi, M.: 1992, Economics, Bounded Rationality and the Cognitive Revolution, Elgar, Aldershot.

Turgot, A. R. J.: 1977, The economics of A. R. J. Turgot, Martinus Nihjoff, The Hague. von Mises, L.: 1959, Human Action, William Hodge, London.

Walras, L.: 1995, Elements of pure economics, or the theory of social wealth, in Hodgson (ed.), Economics and Biology, Augustus Kelley, New York.

Wernerfelt, B.: 1984, A resource-based view of the firm, Journal of Strategic Management (5), 171-180. 